The authors raise the issue of lack of genetic overlap between ADHD in children and adults referring to the European consensus statement on diagnosis and treatment of adult ADHD. ${ }^{3}$ The study does mention that 'to date several publications highlight potential associations with ADHD in adults, some but not all of which are shared with genetic association findings in children', which is again a conclusion they draw from five other pieces of research. This information gets subtly presented in the paper as: there are 'some' similar genes between adult and child ADHD but 'many are different'. Further, the authors state that 'there have been many challenges to the validity of the childhood disorder'. They support this statement with three references, two of which are their own publications

The debate to be had in the clinical world of adult ADHD in the UK is the issue of false positives. Due to the relative lack of stigma of the condition (which is not necessarily a bad thing!) and the issue of diagnostic overlap (particularly with emotionally unstable personality disorders), front-line adult clinicians face a major challenge. Emotional instability is increasingly recognised in adults with $\mathrm{ADHD}^{4}$

With these commonalities in impulsivity and emotional dysregulation the difference between ADHD and emotionally unstable or borderline personality disorder gets blurred in adults (particularly with inclusion of attenuated varieties in DSM-IV) and hinge almost exclusively on 'inattentiveness'. In my opinion, the authors let us down in not exploring in depth these and other real diagnostic and prescribing challenges surrounding adult ADHD.

1 Moncrieff J, Timimi S. Critical analysis of the concept of adult attentiondeficit hyperactivity disorder. Psychiatrist 2011; 35: 334-8.

2 Castells X, Ramos-Quiroga JA, Bosch R, Nogueira M, Casas M. Amphetamines for Attention Deficit Hyperactivity Disorder (ADHD) in adults. Cochrane Database Syst Rev 2011, 6: CD007813.

3 Kooij SJ, Bejerot S, Blackwell A, Caci H, Casas-Brugue M, Carpentier PJ, et al. European consensus statement on diagnosis and treatment of adult ADHD: The European Network. Adult ADHD. BMC Psychiatry 2010; 10: 67

4 Asherson P, Chen W, Craddock B, Taylor E. Adult attention-deficit hyperactivity disorder: recognition and treatment in general adult psychiatry. Br J Psychiatry 2007; 190: 4-5.

Rahul Bhattacharya, consultant psychiatrist, East London NHS Foundation Trust, Honorary Clinical Senior Lecturer, Queen Mary, University of London, UK, email: rahul.bhattacharya@nhs.net

doi: $10.1192 / p b .35 .12 .473 a$

\section{Adult ADHD: problems and pitfalls}

The controversy surrounding adult attention-deficit hyperactivity disorder (ADHD) is intellectually interesting in terms of what it says about the distinction between pathology and normality and our moral response to this. However, the role of psychiatrists is to provide impartial advice to patients about what intervention is likely to be more useful than harmful. The individual then decides whether the intervention is useful for them or not. This applies to any intervention, not only pharmacological.

Considering data may help to inform the debate. I have run a National Health Service adult ADHD clinic for the past 3.5 years, during which time we have received 350 referrals, about half for adults who believe they may have ADHD, but who have not been assessed for this before. Of those who were ultimately identified as having significant ADHD traits and offered pharmacological intervention: (a) 70\% were unemployed or had dropped out of education, (b) $15 \%$ had been in trouble with the police previously, (c) $72 \%$ had had previous contact with mental health services (and no consideration given to the possibility of ADHD), (d) $30 \%$ had two other mental health problems apart from ADHD, (e) $70 \%$ of those prescribed medication (stimulant on non-stimulant) returned to work or education.

It is the last finding that is most telling. These are individuals who are, and have always been, struggling significantly. Medication can help them to successfully complete ordinary but important tasks like hold down a job, stick to a course or maintain personal relationships. It is not a cure, but a powerful tool that can empower the individual.

The psychiatrist has a critical role in diagnosing and prescribing a substance that can have such profound effects (both positive and negative). Perhaps we should focus more on trying to identify who would benefit from intervention, and less on the intellectual exercise involved in 'pathologicising normality'.

Premal J. Shah, consultant psychiatrist, NHS Lothian, Scotland, UK, email: suprem.shah@gmail.com

doi: $10.1192 / p b .35 .12 .474$

\section{Authors' response}

We are glad our article provoked some discussion and we agree with Dr Shah about the need to provide impartial advice and to determine an individual's preferences. Although the outcomes of the adult attention-deficit hyperactivity disorder (ADHD) service he describes are impressive, we do not know that these are attributable to medication alone, rather than other aspects of the care received in a specialist service. Only randomised controlled trials can establish whether medication has specific efficacy, after which effectiveness in real clinical practice and cost:benefit ratios have to be considered. Since we published our paper, the Medicines and Healthcare products Regulatory Agency (MHRA) has withheld approval for methylphenidate hydrochloride for adult ADHD on the basis that differences from placebo are small and do not outweigh documented adverse effects (http://news.wooeb. com/959215/adhd-drug-concerta-disapproved-for-adults-ineurope).

Dr Bhattacharya and Dr Lepping point out that ADHD is conceived as a dimensional rather than a categorical condition, but this does not change the arguments against it. The proposed trait is still defined by 'symptoms' that are universal experiences and diagnosis involves subjective judgements about impairment and what the impairment is caused by. The idea that the symptoms represent a unitary underlying condition that represents an evolution of a childhood disorder is simply an assumption, which is not currently supported by evidence.

Dr Bhattacharya accuses us of being one-sided and not being objective, but we would point out that no one is truly objective and everyone has their own perspective. We would suggest that we are being more objective than others by not 
starting from the presumption that adult ADHD is a useful and valid category. There are numerous articles that provide an opposing point of view. With regard to the randomised trials of drug treatment, since National Institute for Health and Clinical Excellence guidelines are so influential and have endorsed the validity and drug treatment of adult ADHD, it is important to point out the evidence on which these conclusions were reached. We also refer to a meta-analysis of trials of methylphenidate, which found no significant difference in parallel group randomised trials, and the Cochrane review of amphetamines quoted by Dr Bhattacharya also found a lack of evidence of long-term benefit and a high risk of bias.

We do not see that our presentation of the genetic data differs substantially from the way it is presented by Kooij et al, also quoted in Dr Bhattacharya's letter. In any case, we know that most molecular genetic findings are not replicated. The references we used to support the idea that there have been challenges to the concept of childhood ADHD include a book by one of us that was referred to because it reviews the literature in this area, and an article challenging the consensus statement on ADHD that was authored by 32 authors, as well as ourselves.

Dr Bhattacharya and Dr Lepping highlight the problem of comorbidity. The idea that the frequent comorbid conditions are distinct problems, or secondary to ADHD symptoms, rather than competing ways of conceptualising the same problems, is simply an assumption that follows from accepting the diagnosis of adult ADHD. Inattentiveness is too vague a concept to be used to clarify the diagnosis and, given the inclusive nature of inattentiveness 'symptoms', is likely to be identified by most people with mental health problems, as well as many without.

In response to Dr Lepping, studies on levels of the dopamine transporter in ADHD are contradictory, despite the consensus. ${ }^{1}$ Stimulants have well-documented psychoactive effects, and so it is not surprising that they change behaviour in the short term, producing large effects sizes. What is at stake is whether or not they help people in the long term. Evidence in children is not convincing. The Mutimodal Treatment Study of Children with ADHD (the MTA study), which has been criticised on many grounds, found only marginal benefits of a 'medication management' package over behavioural therapy alone or routine community treatment (often including stimulants) at 14 months. ${ }^{2}$ At 3 years there was no difference between the groups, and there was no effect of compliance. ${ }^{3}$ At 8-year follow-up, analysis according to randomised group and actual medication used failed to show any advantage for medication. ${ }^{4}$ Other naturalistic follow-up studies have also failed to demonstrate any advantage for long-term medication in children ${ }^{5}$ and, as we describe in our paper, the evidence in adults is even weaker. Without evidence of long-term benefits, we suggest there is no justification for prescribing medication.

1 Varrone A, Halldin C. Molecular imaging of the dopamine transporter. J Nucl Med 2010; 51: 1331-4.

2 The MTA Cooperative Group. A 14-month randomized clinical trial of treatment strategies for attention-deficit/hyperactivity disorder. The MTA Cooperative Group. Multimodal Treatment Study of Children with ADHD. Arch Gen Psychiatry 1999; 56: 1073-86.

3 Jensen PS, Arnold LE, Swanson JM, Vitiello B, Abikoff HB, Greenhill LL, et al. 3-year follow-up of the NIMH MTA study. J Am Acad Child Adolesc Psychiatry 2007; 46: 989-1002.
4 Molina BS, Hinshaw SP, Swanson JM, Arnold LE, Vitiello B, Jensen PS, et al. MTA at 8 years: prospective follow-up of children treated for combined-type ADHD in a multisite study. J Am Acad Child Adolesc Psychiatry 2009; 48: 484-500.

5 Government of Western Australia Department of Health. Raine ADHD Study: Long-term Outcomes Associated with Stimulant Medication in the Treatment of ADHD in Children. Government of Western Australia Department of Health, 2010.

For the full list of references to this letter, please email the authors.

Joanna Moncrieff, senior lecturer, Department of Mental Health Sciences, University College London, email: j.moncrieff@ucl.ac.uk, Sami Timimi, consultant in child and adolescent psychiatry, Lincolnshire Partnership NHS Foundation Trust, Sleaford, Lincolnshire, UK.

doi: $10.1192 / p b .35 .12 .474 a$

\section{Disclosure of psychiatric records}

The article by Thompson ${ }^{1}$ contains many errors and misleading statements. To begin with, Thompson says that requests from courts for medical records 'are issued by letter'. Courts do not issue requests; they make orders (sometimes referred to as directions). Such orders are never couched in the form of a letter. An order requiring the production of medical records is normally addressed to one of the parties to the proceedings. Such an order would be likely to be addressed to a hospital, National Health Service trust or other such body, or to an individual doctor only when that hospital, trust, other body or doctor had previously failed to disclose the records sought.

The author says that a psychiatrist has the duty to 'seek legal advice from the trust if it appears that clinical information is being requested that is not relevant to the legal issue at stake'. The psychiatrist has no such duty and would be well advised to refrain from expressing any opinion as to whether the records sought are relevant to the issues in the case, and still more so from acting on any such opinion. The psychiatrist is unlikely to have a full appreciation of the legal issues involved. Whether or not he has a correct understanding of the issues, to refuse to release medical records whose disclosure has been directed, on the ground that they are considered not to be relevant to the case clearly defies the authority of the court and is certain to arouse the ire of the judge. An unsympathetic judge might consider it to be contempt of court.

Thompson states that when medical records are released in compliance with a court order, 'third-party information must be removed from case notes'. This is not the case. Section 35 of the Data Protection Act 1998 provides, inter alia: '(1) Personal data are exempt from the non-disclosure provisions where the disclosure is required by or under any enactment, by any rule of law or by the order of a court'. Accordingly, when medical records are released in response to an order of a court they must be disclosed in their entirety, as stipulated in the order. No items should be omitted.

Thompson further says that the psychiatrist's duty of confidentiality 'is not automatically waived by a request from court'. She suggests that a patient could complain to the General Medical Council (GMC) of a breach of confidentiality and that the Council would investigate the complaint. The GMC's guidance on confidentiality states, at paragraph 21: 'You must disclose information if ordered to do so by a judge or presiding officer of a court'. ${ }^{2}$ This, of course, does no more than state the law of the land. However, it is clear that no 